\title{
Current treatment of post-tonsillectomy pain: a review
}

\author{
Santosh Kumar Swain*

\begin{abstract}
Department of Otorhinolaryngology and Head and Neck Surgery, IMS and SUM hospital, Siksha "O” Anusandhan
\end{abstract} \\ University, Kalinga Nagar, Bhubaneswar, Odisha, India
}

Received: 12 July 2021

Revised: 26 August 2021

Accepted: 18 September 2021

\author{
*Correspondence: \\ Dr. Santosh Kumar Swain, \\ E-mail: santoshvoltaire@yahoo.co.in
}

Copyright: () the author(s), publisher and licensee Medip Academy. This is an open-access article distributed under the terms of the Creative Commons Attribution Non-Commercial License, which permits unrestricted non-commercial use, distribution, and reproduction in any medium, provided the original work is properly cited.

\begin{abstract}
Tonsillectomy is one of the most common surgical procedures performed by an otorhinolaryngologist. This surgery is done more in the pediatric age group. Although tonsillectomy is safe and effective surgery, it is usually associated with significant post-operative pain. Analgesics used for post-tonsillectomy pain is often inadequate. Severe throat pain following tonsillectomy has been documented for decades. Patients or parents/caretakers often worry about such severe pain in the home. The pain following tonsillectomy is usually intense and long-lasting. The severe post-tonsillectomy pain often overstrains the patient, family, and hospital staff. Regular changes in the analgesic armamentarium, particularly in pediatric patients are making the treatment of post-tonsillectomy pain more challenging. Pain following the tonsillectomy period continues to be a highly debated issue and an area of active research. Throat pain in the posttonsillectomy period can result in significant morbidity among patients. There are different analgesics available; each one has its risk profile and side effects when used for controlling post-tonsillectomy pain. This review article discusses on recent management of post-tonsillectomy pain. This article reviews the epidemiology, pathophysiology, impact of post-tonsillectomy pain, and details of medications used for controlling post-tonsillectomy pain.
\end{abstract}

Keywords: Tonsillectomy, Post-tonsillectomy pain, Analgesics, Paracetamol

\section{INTRODUCTION}

Tonsillectomy is a common surgical procedure and is often associated with severe throat pain. ${ }^{1}$ There have been many advancements in surgical and anesthetic techniques for faster operations and lesser post-tonsillectomy complications. Pain is an unwanted and unpleasant emotional and sensory experience found in actual or potential tissue injury. ${ }^{2}$ Surgical treatments may result in post-operative pain which also triggers a physiological and biochemical stress response. Tonsillectomy results in severe throat pain, otalgia and cause trismus until exposed and inflamed muscle becomes covered with regenerated mucosal lining.

Pain is an integral part of the post-tonsillectomy period and is often considered intense and lasting for 7 to 10 days. ${ }^{3}$ Patients particularly children may produce restlessness or crying due to pain, hunger, or fear after surgery, particularly tonsillectomy. Tonsillectomy is a commonly performed surgical procedure where the patient often presents with postoperative pain which may challenge the treatment. Inadequate treatment for post-tonsillectomy pain may result in poor oral intake, dehydration. sleep deprivation, behavioral changes, and emesis. ${ }^{4}$

It was suggested that frequent and early oral intake in the post-tonsillectomy period significantly reduces postoperative pain. ${ }^{5}$ Oral analgesics are usually prescribed for post-tonsillectomy pain and these oral analgesics are often insufficient, and despite parenteral opioids being effective, these may result in sedation, respiratory depression, constipation, nausea, and vomiting. ${ }^{6}$

This review article describes details of epidemiology, pathophysiology, the impact of post-tonsillectomy pain on patients, and therapy used for controlling posttonsillectomy pain. 


\section{METHODS OF LITERATURE SEARCH}

We performed a literature review of the management of post-tonsillectomy pain in patients consisting of data base of Pubmed, Medline, Scopus, and Google scholar search with terms post-tonsillectomy pain, management of posttonsillectomy pain, the pathophysiology of posttonsillectomy pain, and medications used for posttonsillectomy pain. We reviewed different current articles published in national and international journals.

This manuscript reviews the details of management of post-tonsillectomy pain its epidemiology, pathophysiology, the impact of post-tonsillectomy on patient and family, medications used for managing posttonsillectomy pain. This review article surely makes a baseline from where further prospective studies can be designed for the management of post-tonsillectomy pain which can help to prevent this morbid clinical entity.

\section{EPIDEMIOLOGY}

One study showed 2,50,000 adenotonsillectomies were performed in the United States every year. ${ }^{7}$ As per data from the Centers for Disease Control and Prevention, over 737,000 ambulatory tonsillectomies were performed in the United States in $2006 .{ }^{8}$ A study from Denmark showed $1,53,212$ patients underwent tonsillectomies with 84,831 females and 68,381 males during 1980 to 2001 where the age-specific incidence of tonsillectomy peaked at the age of 4 years for both boys and girls with 9.7 and 6.9 tonsillectomies per 1000 person per year respectively. ${ }^{9}$

There has been written about the benefits of tonsillectomy in respect to postoperative improvement of the quality of life and behavior of the patient. Tonsillectomy is one of the most common surgeries done by otolaryngologists which may cause severe pain following tonsillectomy. ${ }^{10}$ Posttonsillectomy pain is an expected sequel of this procedure which typically lasts from 7 to 10 days. ${ }^{10}$ The posttonsillectomy may be moderate to severe in intensity. Some patients with post-tonsillectomies often need readmission to the hospital for management of their pain along with management of the dehydration due to poor oral intake of fluids because of such pain. ${ }^{11}$

\section{PATHOPHYSIOLOGY TONSILLECTOMY PAIN}

OF

POST-

Post-tonsillectomy pain can occur for different reasons and also the pain can ensue simply from the positioning of the patient during tonsillectomy. ${ }^{12}$ The placement of the Boyle-Davis mouth gag itself can cause pressure and venous congestion of the tongue which results in postoperative pain and swelling as well as stretching of the temporomandibular joint. Tonsillectomy creates large areas of the exposed muscle in the oropharynx, leading to considerable pain from the spasm of the muscle and irritation of the nerve endings. ${ }^{13}$
Excessive dissections and use of cautery hemostasis during tonsillectomy may produce greater incidence of inflammation and post-operative pain. ${ }^{14}$ Patients with post-tonsillectomies often complain of ear pain, presumably referred otalgia which occurs through a glossopharyngeal nerve. Removal of the tonsil triggers the inflammatory process which facilitates the healing process at the tonsillar fossa area but also leaves an open wound that exposes the nerve fibers and damaged muscle fibers. ${ }^{15}$

This make post-operative wound vulnerable to mechanical injury during eating or swallowing. Post-tonsillectomy wound shows evidence of inflammation and infection by producing a thick fibrin layer which increases in size by the first 3 to 4 days postoperatively. ${ }^{16}$ This fibrin layer begins to shed at approximately 7 days and then allows the bed to remucosalize by the end of the second week. ${ }^{17} \mathrm{By}$ this healing process, postoperative pain can be manifested in a biphasic pattern with a peak at around 3 to 7 days but may persist for 2 to 3 weeks following surgery. ${ }^{17}$ Poorly treated post-tonsillectomy pain may result in distress for both patients and parents in the case of children. It also causes dehydration of the patient because of less intake of fluid and food. The treatment of post-tonsillectomy pain is always the priority in patients, particularly in children.

\section{IMPACT OF POST-TONSILLECTOMY PAIN}

Post-tonsillectomy pain is the most significant obstacle for the rehabilitation of a patient by influencing the period of hospital stay and the ability to return to routine activity. The important factors which decide the post-operative outcomes are pain, nausea, and vomiting, anxiety before surgery, and discomfort by intravenous injection. ${ }^{18}$ It has been seen that more than $60 \%$ of the pediatric patients those underwent tonsillectomy exhibit negative behavioral changes in the next weeks after surgery. ${ }^{19}$ So, it is important to prescribe effective postoperative analgesics in children. Many otolaryngologists think the severity of pain is worse between day three and day five following tonsillectomy. ${ }^{20}$ However, there is no such evidence to support this.

\section{ACETAMINOPHEN}

Acetaminophen or paracetamol is commonly used in the post-tonsillectomy period as an analgesic and antipyretic. It is a very safe drug for inpatients and often associated with very few side effects than non-steroidal antiinflammatory drugs (NSAIDS). ${ }^{21}$ Paracetamol is usually used as the first line of treatment for any surgical pain and found to be an effective analgesic for managing posttonsillectomy pain. ${ }^{22}$ However, for getting maximum pain control, paracetamol is often used along with NSAID as a combination. ${ }^{23}$ Intra-operative acetaminophen administrations give rise to adequate postoperative analgesia in pediatric age group those undergoing tonsillectomy. The intravenous paracetamol significantly improves the throat pain following tonsillectomy. ${ }^{24}$ 


\section{NON-STEROIDAL DRUGS \\ ANTI-INFLAMMATORY}

NSAIDs are highly effective for the treatment of mild and moderate pain. ${ }^{25}$ These are considered potent analgesics by inhibiting cyclooxygenase enzymes which mediate inflammation and pain. ${ }^{26}$ These also block throboxane, an important mediator in platelet aggregation, which potentially leads to an increased chance of bleeding. Many surgeons avoid the use of NSAIDs for relieving postoperative pain.

However, the study is failed to prove the chance of bleeding when comparing the NSAIDs with other analgesics. $^{27}$ It has been documented that NSAIDs controlled post-operative pain similar to opioids. ${ }^{28}$ NSAIDs also reduce the chance of post-operative vomiting in comparison to both opioids and non-opioids. ${ }^{29}$ Overall, the use of NSAIDs is increasing widely for post-operative tonsillectomy pain control and must be considered as firstline treatment in respect to acetaminophen.

\section{TRAMADOL}

Tramadol is a centrally acting analgesic with weak opioid agonist activity. The safety of tramadol is well established with no evidence of respiratory depression, low dependence, and abuse potential.

All these properties are suitable for managing posttonsillectomy pain. ${ }^{30}$ One study reported the analgesic effect of the topical tramadol for controlling postoperative pain in the pediatric population after tonsillectomy where they concluded that topical $5 \%$ tramadol seems to be the safe, easy and comfortable approach for pain management in children undergoing tonsillectomy. ${ }^{31}$

\section{ROLE OF INTRA-OPERATIVE STEROID}

Administration of steroids is often done in several diseases of otorhinolaryngology. ${ }^{32}$ Intra-operative steroids are often used to control postoperative nausea and vomiting, particularly in pediatric tonsillectomy. ${ }^{33}$ Study shows that post-operative steroids can control pain and make painfree post-operative periods by use of oral steroids. ${ }^{34}$ However, there is controversy regarding post-operative bleeding from the tonsillar fossa by use of systemic steroids. ${ }^{35}$ One study from Japan stated that higher chance of bleeding and re-surgery for hemostasis after tonsillectomy in children those administered with systemic steroids for prophylaxis of nausea and vomiting after surgery. ${ }^{36}$ However, larger prospective studies are required to determine the role of steroids and their safety profile in the pediatric age group.

\section{LIDOCAINE, KETAMINE, AND MORPHINE TOPICAL SPRAY}

Lidocaine, ketamine, and morphine sprays are more effective than a placebo for controlling postoperative pain.
However, these three medications have different actions of onset. At the beginning of the recovery time, lidocaine produces the best analgesia, ketamine gives lesser analgesia than lidocaine but morphine does not have an analgesic effect at this period. ${ }^{37}$ So, a combination of lidocaine with one of the morphine or ketamine sprays is useful to find better methods to produce posttonsillectomy analgesia in children. The analgesic spray is an ideal method for post-operative pain control. This spray is delivered by a pump or pressurized container. The analgesic spray is topical and applied on the surface of the tonsillectomy fossa. The topical spray of morphine generates a localized analgesic effect in the mucosa tissue. Topical anesthetic or antiseptic medications like chlorhexidine gluconate $(0.12 \%)$ and benzydamine HCL $0.15 \%$ spray is a topical agent which shows antiseptic, anti-inflammatory, and analgesic effects. It can be used after tonsillectomy for reducing post-operative pain. ${ }^{38}$ Topical anesthetics have not proven to decrease posttonsillectomy pain. It also hampers the oral intake of food by diminishing the sense of taste. One study showed benzocaine lozenge to placebo and shown no difference in pain or the number of analgesics used. ${ }^{39}$

\section{ROPIVACAINE, BUPIVACAINE AND LIDOCAINE}

A local anesthetic agent infiltrated into the peritonsillar space or tonsillar bed provides analgesia with minimal side effects. This helps control post-tonsillectomy pain and intra-operative bleeding. During the intra-operative period, pain impulses enter into the central nervous system which creates a hyperexcitable state despite general anesthesia. If these impulses are blocked by preoperative/intra-operative analgesic drugs by infiltration or topical administration of local anesthetic drugs result in inadequate analgesic effect following tonsillectomy. ${ }^{40}$

Ropivacaine is a member of the amino amide group of local anesthetics which blocks the generation and conduction of neural impulses similar to bupivacaine. ${ }^{41}$ In tonsillectomy, $0.25 \%$ bupivacaine with $1: 2,00,000$ epinephrine, typically 3 to $5 \mathrm{ml}$ is injected into the peritonsillar tissue before or after removal of the tonsils are helpful to control post-tonsillectomy. ${ }^{42}$ However, $0.5 \%$ lidocaine with 1:1,00,000 epinephrine and ropivacaine with or without clonidine.

Ropivacaine is 2 to 3 times less soluble and has a lesser volume of distribution, more clearance, and shorter elimination half-life than bupivacaine in humans. ${ }^{41}$

\section{KETAMINE INFILTRATION}

Ketamine infiltration into the tonsillar fossa immediately after tonsillectomy is found to be effective for postoperative pain control and without adverse effects. Ketamine, an N-methyl-D-aspartate (NMDA) receptor antagonist has a potent analgesic effect with subanesthetic doses. Intra-operative intravenous ketamine with a dose of $0.15 \mathrm{mg} / \mathrm{kg}$ is found to be effective in post-tonsillectomy 
pain management. ${ }^{43}$ Analgesia by ketamine differs from local anesthetics by blocking central perception of pain as in other NMDA antagonists. Bupivacaine infiltration along with ketamine prolongs local analgesia time and may stay for one week after infiltration. ${ }^{44}$

\section{SUCRALFATE}

Sucralfate is a basic aluminum salt of a sulfated disaccharide which forms a barrier along with mucoproteinaceous layer at duodenal ulcers. This barrier usually protects the tissues from the erosive and irritating effects of gastric acid and pepsin. Similarly, sucralfate forms a protective barrier in the wound in the tonsillar fossa following tonsillectomy which decreases the painful irritation and muscle spasm and also enhances the healing. ${ }^{45}$

After completion of tonsillectomy, the oropharynx is irrigated with $60 \mathrm{ml}$ solution containing one gram of sucralfate powder, and then each patient is suggested to swallow the same solution four times daily for 10 days. $^{45}$

\section{HONEY}

Tonsillectomy with or without adenoidectomy is a commonly performed surgical procedure done worldwide, particularly in the pediatric age group. Oral administration of honey following tonsillectomy in children may decrease the requirement of analgesics for relieving postoperative pain. ${ }^{46}$ Honey speeds up the healing process in the wound by stimulating the production of inflammatory cytokines from monocytes and keratinocytes. ${ }^{47}$

Nitric oxide and prostaglandins play a vital role in the inflammation, microbial killing, and healing process of the wound. Honey is found to reduce prostaglandin levels and increase nitric oxide end products. These properties of the honey help to explain its therapeutic properties as an antibacterial agent or wound healing. ${ }^{48}$ The side effects of honey are almost negligible and so suggested for routine use along with analgesics in the post-tonsillectomy period.

\section{ANALGESICS FOR POST-TONSILLECTOMY PAIN AND OSAS}

Many pediatric patients undergo adenotonsillectomy for Obstructive sleep apnea syndrome (OSAS). Although adenotonsillectomy is the treatment in patients with OSAS, the respiratory parameters may not improve just after surgery. Consequently, these pediatric patients may be more sensitive to opioids and particularly vulnerable to respiratory complications due to opioid use. ${ }^{49}$ Some pediatric patients may need opioids for post-tonsillectomy pain but do not require to be adjusted downward to reflect this sensitivity to opioids.

One study comparing the safety and efficacy of morphine to ibuprofen for treatment of post-tonsillectomy pain where approximately $86 \%$ of children with morphine had more desaturation on the night following surgery, with an average increase of eleven episodes of desaturation per hour. ${ }^{49}$

Conversely, approximately $68 \%$ of the pediatric patients with ibuprofen shows less desaturation after surgery with an average improvement of two fewer desaturations per hour in comparison to pre-operative measurement. A child with morphine was seen to be unresponsive with features of cyanosis and required oxygen supplementation and intravenous naloxone before recuperating. However, morphine is no longer routinely used in the posttonsillectomy period, and if prescribed, the caretakers/parents are instructed about the risks and safety of this medication. In case of severe OSAS under the age of three, have associated craniofacial or medical issues or need more morphine for analgesia where they are often admitted to hospital for overnight oxygen monitoring. ${ }^{50}$

\section{POST-TONSILLECTOMY PAIN AND TECHNIQUE OF TONSILLECTOMY}

There are several factors associated with the intensity of post-tonsillectomy pain. The minimal and precise dissection confined to natural planes and minimal use of the electro-cautery or coblation may reduce the pain in the post-tonsillectomy period..$^{51}$

Infiltration of the anesthetic agent into the peritonsillar space provides short-term relief of pain following tonsillectomy. Perioperative use of antibiotics may decrease the infection which contributes to the inflammation and muscle spasm resulting in pain. Coblation tonsillectomy with the expert hand is a safe and effective surgical procedure in comparison to other techniques in terms of post-tonsillectomy pain and hemorrhage.$^{51}$ Following tonsillectomy, early and frequent oral intake in the post-operative period significantly reduces the post-tonsillectomy pain. ${ }^{5}$

\section{CRYOANALGESIA}

The reduction of pain following the post-tonsillectomy period is an important challenge for a clinician, not because of patient comfort, but also for improvement of oral intake which decreases the risk of dehydration, infection, and post-tonsillectomy hemorrhage. Cryoanalgesia is a new technique aimed to reduce posttonsillectomy pain.

Patients who undergo cryoanalgesia return to work or school, on average four days earlier than those who had not undergone cryoanalgesia. ${ }^{52}$ Cryoanalgesia requires the insertion of two needles superficially into the tonsillar fossa. Each cooling application stays for 60 seconds with a probe temperature of $-56^{\circ} \mathrm{C}$ which provides tissue temperature of $-20^{\circ} \mathrm{C}$ to $-32^{\circ} \mathrm{C} .{ }^{52}$ In this technique, cooling of the tissue reduces the inflammation, probably via vasoconstriction and subsequent decreasing edema and pain-producing mediators. Cooling of the nerve fibers 
reduces their conduction at a rate proportional to the degree of temperature.

\section{CONCLUSION}

Tonsillectomy is a common daycare surgical procedure and is associated with significant post-operative pain. There are several factors to be considered when treating post-tonsillectomy pain. Patient's factors such as indications of tonsillectomy, co-morbidities, caregiver circumstances, and other related clinical history are required when deciding on exact therapeutic agents. Acetaminophen should be considered as a workhorse analgesic for treating post-tonsillectomy pain. However, care should be taken and avoidance of NSAIDs is warranted for the history of bleeding disorders, recurrent bleeding, kidney failure, or peptic ulcer disease as well as asthmatic or allergic reactions to NSAIDs.

Funding: No funding sources

Conflict of interest: None declared

Ethical approval: Not required

\section{REFERENCES}

1. Joshi W, Connelly NR, Reuben SS, Wolckenhaar M, Thakkar N. An evaluation of the safety and efficacy of administering rofecoxib for postoperative pain management. Anesth Analg. 2003;97(1):35-8.

2. Gehdoo R. Postoperative pain management in pediatric patients. Indian J Anaesth. 2004;48(5):40614.

3. Scalford D, Roth R, Howard D, Phillips E, Ryan E, Davis KF, et al. Pain management of children aged 5 to 10 years after adenotonsillectomy. J Perianesth Nurs. 2013;28(6):353-60.

4. Sutters KA, Miaskowski C. Inadequate pain management and associated morbidity in children at home after tonsillectomy. J Pediatr Nurs. 1997;12(3):178-85.

5. Chaturvedi J, Vamanshankar H, Chandrashekar S, Manikantan K, Nayar RC. An assessment of postoperative pain in patients undergoing tonsillectomy. Otorinolaringologia. 2010;60(4):23943.

6. Walco GA, Cassidy RC, Schechter NL. Pain, hurt, and harm: the ethics of pain control in infants and children. N Engl J Med. 1994;331:541-4.

7. Shinhar S, Scotch BM, Belenky W, Madgy D, Haupert M. Harmonic scalpel tonsillectomy versus hot electrocautery and cold dissection: an objective comparison. Ear Nose Throat J. 2004;83(10):712-5.

8. Cullen KA, Hall MJ, Golosinsky A. Ambulatory surgery in the United States, 2006. Natl Health Stat Rep. 2009;11:1-28.

9. Vestergaard H, Wohlfahrt J, Westergaard T, Pipper C, Rasmussen N, Melbye M. Incidence of tonsillectomy in Denmark, 1980 to 2001. Pediatr Infect Dis J. 2007;26(12):1117-21.
10. Swain SK, Sahu MC, Choudhury J, Ananda N. Adenotonsillectomy affecting quality of life in pediatric patients: Our experiences at a tertiary care teaching hospital of Eastern India. Annals of Indian Acad Otorhinolaryngol Head Neck Surg. 2020;4(1):1-4.

11. Swain SK, Debta P, Sahoo S, Samal S, Sahu MC, Mohanty JN. An Unusual Cause of Throat Pain: A Case Report. Indian J Public Health Res Develop. 2019;10(11):1029-31.

12. Swain SK, Jena A, Sahu MC, Banerjee A. Eagle's Syndrome: Our experiences in a tertiary care teaching hospital of Eastern India. J Head Neck Physician Surg. 2017;5(2):66-70.

13. Swain SK, Choudhury J. Experience with the management of pediatric laryngopharyngeal reflux in an Indian teaching hospital. J Clinical Sci. 2020;17(3):61-5.

14. Bhadoria P, Rathore PK, Mandal S, Sehgal R, Meher $\mathrm{R}$, Singh R. Role of Bupivacaine in reducing post tonsillectomy pain. Indian J Otolaryngol Head Neck Surg. 2006;58(4):335-6.

15. Swain SK, Das A, Nahak B, Behera IC. Microscope assisted coblation tonsillectomy: a safe and effective surgical technique. Int J Otorhinolaryngol Head Neck Surg. 2019;5(5):1446-50.

16. Sutters KA, Isaacson G. Posttonsillectomy pain in children. Am J Nurs. 2014;114(2):36-42.

17. Isaacson G. Tonsillectomy healing. Ann Otol Rhinol Laryngol. 2012;121(10):645-9.

18. Swain SK, Ghosh TK, Munjal S, Mohanty JN. Microscope-assisted coblation tonsillectomy among paediatric patients-our experiences at an indian teaching hospital. Pediat Polska- Polish J Paediat. 2019;94(3):170-4.

19. Hosseini JSA, Hosseini VSM, Naseh N. A comparison of the effect of oral paracetamol and clonidine on pediatric preoperative anxiety in adenotonsillectomy. Pak J Med Sci. 2009;25(3):45861.

20. Swain SK, Debta P. Aspergillosis of the palatine tonsil. Annals Indian Acad Otorhinolaryngol Head Neck Surg. 2020;4(2):50-2.

21. Pierce CA, Voss B. Efficacy and safety of ibuprofen and acetaminophen in children and adults: a metaanalysis and qualitative review. Ann Pharmacother. 2010;44(3):489-506.

22. Merry AF, Edwards KE, Ahmad Z, Barber C, Mahadevan M, Frampton C. Randomized comparison between the combination of acetaminophen and ibuprofen and each constituent alone for analgesia following tonsillectomy in children. Can J Anaesth. 2013;60(12), 1180-9.

23. Martin SD, John LD. Implications of a Retrospective Study on Weight-Based Risk for Post-Tonsillectomy Pain in Children. J Perianesth Nurs. 2020;35(2):1406.

24. Swain SK, Anand N, Sahu MC. Peripheral facial nerve palsy-A rare complication of tonsillectomy. 
Annals Indian Academy Otorhinolaryngol Head Neck Surg. 2020;4(1):10-2.

25. Salonen A, Kokki H, Nuutinen J. Recovery after tonsillectomy in adults: a three-week follow-up study. Laryngoscope. 2002;112(1):94-8.

26. Gallagher TQ, Wilcox L, Guire E, Derkay CS. Analyzing factors associated with major complications after adenotonsillectomy in 4776 patients: comparing three tonsillectomy techniques. Otolaryngol Head Neck Surg. 2010;142(6):886-92.

27. Riggin L, Ramakrishna J, Sommer DD, Koren G. A 2013 updated systematic review \& meta-analysis of 36 randomized controlled trials; no apparent effects of non steroidal anti-inflammatory agents on the risk of bleeding after tonsillectomy. Clin Otolaryngol. 2013;38(2):115-29.

28. Lijewski JD, Kruitbosch SH, Hutchinson L, Browne B. Post-tonsillectomy pain management in children: can we do better?. Otolaryngol Head Neck Surg. 2007;137(4):545-51.

29. Swain SK, Pradhan C, Mohanty S, Sahu MC. Comparative study between selective nerve blocks and the intravenous opioids in mastoid surgery. Egyptian J Ear Nose Throat Allied Sci. 2017;18(2):121-5.

30. Kongara K, Chambers JP, Johnson CB. Effects of tramadol, morphine or their combination in dogs undergoing ovariohysterectomy on peri-operative electroencephalographic responses and postoperative pain. New Zealand Veterinary J. 2012;60(2):129-35.

31. Akbay BK, Yildizbas S, Guclu E, Yilmaz S, Iskender A, Ozturk O. Analgesic efficacy of topical tramadol in the control of postoperative pain in children after tonsillectomy. J Anesth. 2010;24(5):705-8.

32. Swain SK, Behera IC, Sahu MC. Head injury with sudden onset bilateral facial palsy-Can happen without temporal bone fractures and brain injury!. Egyptian J Ear Nose Throat Allied Sci. 2016;17(1):23-5.

33. Steward DL, Grisel J, Derr J. Steroids for improving recovery following tonsillectomy in children. Cochrane Database Syst Rev. 2011;2011(8):3997.

34. Park SK, Kim J, Kim JM, Yeon JY, Shim WS, Lee DW. Effects of oral prednisolone on recovery after tonsillectomy. Laryngoscope. 2015;125(1):111-7.

35. Bellis JR, Pirmohamed M, Nunn AJ, Loke YK, De S, Golder S, et al. Dexamethasone and haemorrhage risk in paediatric tonsillectomy: a systematic review and meta-analysis. Br J Anaesth. 2014;113(1):23-42.

36. Suzuki S, Yasunaga H, Matsui H, Horiguchi H, Fushimi K, Yamasoba T. Impact of systemic steroids on posttonsillectomy bleeding: analysis of 61430 patients using a national inpatient database in Japan. JAMA Otolaryngol Head Neck Surg. 2014;140(10):906-10.

37. Hosseini JSA, Hosseini VSM, Hatamian S. Comparison between effect of lidocaine, morphine and ketamine spray on post-tonsillectomy pain in children. Anesth Pain Med. 2012;2(1):17-21.
38. Ozkırış M, Mutlu C. The effects of post-operative topical chlorhexidine gluconate and benzydamine HCL spray (farhex) on postoperative pain and oral intake in tonsillectomied patients. $\mathrm{J}$ Med Med Sci. 2011;2(10):1143-6.

39. Demster JH. Post-tonsillectomy analgesia: The use of Benzocaine Lozenges. J Laryngol Otol. 1988;102:813-4.

40. Nunez DA, Provan J, Crawford M. Postoperative tonsillectomy pain in pediatric patients: electrocautery (hot) vs cold dissection and snare tonsillectomy--a randomized trial. Arch Otolaryngol Head Neck Surg. 2000;126(7):837-41.

41. Akoglu E, Akkurt BC, Inanoglu K, Okuyucu S, Dagli S. Ropivacaine compared to bupivacaine for posttonsillectomy pain relief in children: a randomized controlled study. Int $\mathrm{J}$ Pediatr Otorhinolaryngol. 2006;70(7):1169-73.

42. Nikandish R, Maghsoodi B, Khademi S, Motazedian S, Kaboodkhani R. Peritonsillar infiltration with bupivacaine and pethidine for relief of posttonsillectomy pain: a randomised double-blind study. Anaesthesia. 2008;63(1):20-5.

43. Flaherty JE, Lin CX. Does ketamine or magnesium affect posttonsillectomy pain in children?. Paediatr Anaesth. 2003;13(5):413-21.

44. Tverskoy M, Oren M, Vaskovich M, Dashkovsky I, Kissin I. Ketamine enhances local anesthetic and analgesic effects of bupivacaine by peripheral mechanism: a study in postoperative patients. Neurosci Lett. 1996;215(1):5-8.

45. Freeman SB, Markwell JK. Sucralfate in alleviating post-tonsillectomy pain. Laryngoscope. 1992;102(11):1242-6.

46. Boroumand P, Zamani MM, Saeedi M, Rouhbakhshfar O, Hosseini MSR, Aarabi MF. Post tonsillectomy pain: can honey reduce the analgesic requirements?. Anesth Pain Med. 2013;3(1):198202.

47. Benhanifia MB, Boukraâ L, Hammoudi SM, Sulaiman SA, Manivannan L. Recent patents on topical application of honey in wound and burn management. Recent Pat Inflamm Allergy Drug Discov. 2011;5(1):81-6.

48. Waili N, Salom K, Ghamdi AA. Honey for wound healing, ulcers, and burns; data supporting its use in clinical practice. Sci World J. 2011;11:766-87.

49. Kelly LE, Sommer DD, Ramakrishna J, Hoffbauer S, Tafti S, Reid D, et al. Morphine or Ibuprofen for posttonsillectomy analgesia: a randomized trial. Pediatrics. 2015;135(2):307-13.

50. Baugh RF, Archer SM, Mitchell RB, Rosenfeld RM, Amin R, Burns JJ, et al. Clinical practice guideline: tonsillectomy in children. Otolaryngol Head Neck Surg. 2011;144(1):1-30.

51. Swain SK, Ghosh TK, Das A. Microscope-Assisted coblation tonsillectomy: Our experiences at a tertiary care teaching hospital of eastern India. Annals of Indian Academy of Otorhinolaryngol Head Neck Surg. 2020;4(2):35-8. 
52. Robinson SR, Purdie GL. Reducing posttonsillectomy pain with cryoanalgesia: a randomized controlled trial. Laryngoscope. 2000;110(7):112831 .
Cite this article as: Swain SK. Current treatment of post-tonsillectomy pain: a review. Int $\mathrm{J}$

Otorhinolaryngol Head Neck Surg 2021;7:1708-14. 